\title{
Efeito do tempo de jejum pós-eclosão, valores energéticos e inclusão do ovo desidratado em dietas pré-iniciais e iniciais de pintos de corte
}

\section{Elisanie Neiva Magalhães Teixeira ${ }^{1}$, José Humberto Vilar da Silva ${ }^{2}$, Fernando Guilherme Perazzo Costa ${ }^{3}$, Terezinha Domiciano Dantas Martins ${ }^{4}$, Patrícia Emília Naves Givisiez ${ }^{4}$, Dermeval Araújo Furtado ${ }^{5}$}

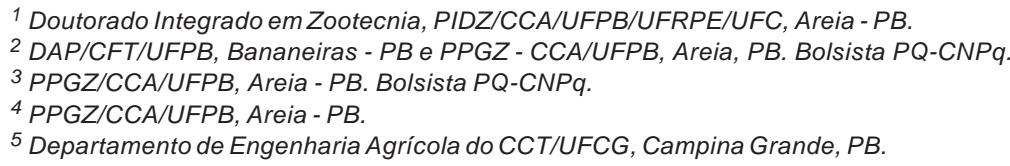

RESUMO - Dois experimentos foram realizados para determinar o valor nutricional do ovo desidratado (OD), o efeito do tempo de jejum pós-eclosão (TJPe) e a inclusão do ovo desidratado em rações para frangos de corte. No primeiro experimento, 120 pintos de corte machos, linhagem Ross-308, foram alojados em delineamento inteiramente casualizado, com três tratamentos e cinco repetições de oito aves. As coletas de excretas foram realizadas no período de 24 a 29 dias de idade, pela manhã e à tarde. No segundo experimento, um lote misto de 810 pintos da linhagem Cobb-500, com peso vivo inicial 33,41 \pm 0,53, foi alojado em boxes de 1,0 $\times 1,5 \mathrm{~m}$. O delineamento experimental utilizado foi o inteiramente casualizado com 9 tratamentos e 6 repetições de 15 aves, em esquema fatorial $3 \times 3$, com três níveis de ovo desdratado (0, 2 e $4 \%)$ e três tempos de jejum pós-eclosão (28, 40 e 52 horas), correpondentes a 0, 12 e 24 horas de jejum pós-alojamento, respectivamente. O ovo desidratado apresentou 51,54\% de PB e 4.278 kcal EMAn. Na fase de 1 a 7 dias, o peso vivo, o ganho de peso e o consumo de ração entre as aves submetidas a jejum de 40 e 52 horas foram inferiores aos daquelas alimentadas mais cedo (às 28 horas do tempo de jejum pós-eclosão), enquanto as aves submetidas a 52 horas de jejum pós-eclosão (24 horas de jejum pós alojamento) apresentaram os piores resultados. O nível de $4 \%$ de ovo desidratado na ração pré-inicial melhorou o peso vivo no segundo e terceiro dia de idade dos pintinhos. No período de 1 a 21 dias, o ovo desidratado pode ser utlizado na alimentação de frangos, pois não prejudica o desempenho das aves.

Palavras-chave: alimento alternativo, desempenho, desenvolvimento inicial, valor nutritivo

\section{Effect of post-starvation hatching time, energy levels and addition of dried egg in pre-initial and initial diets for broiler chicks}

\footnotetext{
ABSTRACT - Two experiments were carried out to determine the nutritional value of the dried egg (DEGG), and the effect of the post-starvation hatching time (PSHT) and the inclusion of dried egg powder in the diet of broiler chicks. In experiment 1, 120 male Ross-308 broiler chicks were housed according to a completely randomized design into three treatments and five repetitions of eight birds each. Excreta collection was daily performed from 24 to 29 days of age in the morning and afternoon. In experiment 2, a sex-mixed batch of 810 Cobb-500 chicks was used. Initial weight was $33.41 \pm 0.53 \mathrm{~g}$, and the chicks were housed in pens measuring $1.0 \times 1.5 \mathrm{~m}$. A completely randomized experimental design was used with nine treatments and six repetitions of 15 birds each, according to a $3 \times 3$ factorial of three DEGG levels (0, 2 and $4 \%)$ and three PSHT (28, 40 and 52 hours), corresponding to: 0,12 and 24 hours of starvation after housing, respectively. DEGG showed $51.54 \%$ of CP and 4,278 kcal AMEn/kg. From 1 to 7 days of age, the birds submitted to starvation for 40 and 52 hours showed lower live weight, weight gain and feed intake when compared to birds fed sooner (at 28 hours PSHT). The poorest performance was shown by birds fasted for 52 hours ( 24 hours of starvation after being housed). DEGG levels of $4 \%$ in the pre-initial diet improved the live weight in the second and third days of age. In conclusion, DEGG might be used from 1 to 21 days of age in broiler diets without impairing the bird performance.
}

Key Words: alternative feed, initial development, nutritional value, performance

Este artigo foi recebido em 24/9/2007 e aprovado em 31/7/2008.

Correspondências devem ser enviadas para: elisanieteixeira@yahoo.com.br 


\section{Introdução}

As decisões mais importantes nas formulações de rações para frangos de corte estão relacionadas às concentrações de proteína (aminoácidos) e energia, cujos níveis influenciam tanto o custo da ração quanto o desempenho das aves.

Após a eclosão, o desenvolvimento inicial do pintinho é fundamental para melhor desempenho do frango de corte até o final do ciclo de produção. A alta correlação entre o peso corporal na fase pré-inicial e a idade de abate é um indicador da influência do manejo nutricional nas primeiras horas de vida sobre o crescimento de pintos de corte (Junqueira et al., 2001).

A fase pré-inicial representa $17 \%$ do período de vida de um frango de corte (Lilburn, 1998) e o uso de formulações específicas para pintos de corte neste período é o reconhecimento da precocidade das linhagens de corte, o que exige reavaliações das práticas nutricionais para acompanhar estas mudanças em benefício da moderna avicultura (Vieira \& Pophal et al., 2000).

De acordo com Vieira \& Pophal et al. (2000), o tempo gasto com sexagem, vacinação e transporte pode atrasar o alojamento e a alimentação dos pintos e, neste caso, a presença do saco vitelino é vital para garantir a sobrevivência da ave nas primeiras horas de vida. Segundo Noy \& Sklan (1999), é provável que o atraso no fornecimento de ração na fase pós-eclosão afete o ganho de peso dos frangos à idade de abate, visto que os nutrientes do resíduo da gema são insuficientes para melhorar o desempenho dos pintos nos primeiros dias de idade. Vieira \& Pophal (2000) sugeriram abreviar o tempo de alojamento para garantir maior conforto e bem-estar aos pintos após o período de estresse do nascimento ao alojamento.

Segundo Figueiredo (2003), entre os ingredientes utilizados em rações para aves na fase inicial, o ovo é uma opção que precisa ser estudada, pois é fonte de proteína animal de excelente qualidade. Norberg et al. (2004) determinaram em patos a EMAn e EMVn, os aminoácidos digestíveis aparente e verdadeiros do ovo em pó, da proteína do plasma e do farelo de soja e encontraram valores de EMAn de $5.048 \mathrm{kcal} / \mathrm{kg}$ para o ovo em pó, enquanto a digestibilidade de metionina, histidina e valina foi maior no ovo em pó em comparação ao plasma sanguíneo e ao farelo de soja.

A quebra e a trinca da casca dos ovos produzem quantidade significativa de subprodutos impróprios para o consumo humano. Silva et al. (2006) demonstraram que a adição de $0,6 \%$ de ovo desidratado na dieta pré-inicial de pintinhas estimulou o desempenho das aves em relação à dieta convencional, à base de milho e de farelo de soja.
Entretanto, Junqueira et al. (2001) encontraram efeitos negativos da adição de 5; 10; 20 e 25\% de ovo desidratado no desempenho inicial de pintos de corte.

Objetivou-se com este trabalho determinar os valores nutricionais e avaliar a inclusão do ovo desidratado na alimentação de pintos de corte submetidos a diferentes tempos de jejum pós-eclosão.

\section{Material e Métodos}

Dois experimentos foram conduzidos; o primeiro foi desenvolvido no Campus de Areia, da Universidade Federal da Paraíba (UFPB), utilizando-se 120 pintos de corte machos, linhagem Ross, com 19 dias de idade, alojados em delineamento inteiramente ao acaso, em bateria do tipo “Brasília”, com três níveis (0, 15 ou 30\%) de ovo desidratado na ração, cada um com cinco repetições de oito aves.

A composição alimentar e nutricional da ração-referência (Tabela 1) foi calculada segundo recomendações de Rostagno et al. (2000).

Tabela 1 - Composição da ração-referência na matéria natural (experimento 1$)^{1}$

\begin{tabular}{|c|c|}
\hline Ingrediente & $\%$ \\
\hline Milho & 58,939 \\
\hline Farelo de soja & 35,234 \\
\hline Óleo de soja & 1,862 \\
\hline Calcário & 0,988 \\
\hline Fosfato bicálcico & 1,816 \\
\hline DL-metionina & 0,234 \\
\hline L-lisina. $\mathrm{HCl}$ & 0,174 \\
\hline Premix vitamínico ${ }^{2}$ & 0,100 \\
\hline Premix mineral ${ }^{3}$ & 0,100 \\
\hline Promotor de crescimento 4 & 0,010 \\
\hline Anticcocidiano $^{5}$ & 0,010 \\
\hline Amido & 0,015 \\
\hline Caulim ${ }^{7}$ & 0,518 \\
\hline
\end{tabular}

Composição química

Proteína bruta (calculada) 21,40

Proteína bruta (analisada) ${ }^{6} \quad 21,00$

EMAn (kcal) 3.000

Cálcio (\%) $\quad 0,960$

Fósforo disponível (\%) 0,450

Metionina (\%) $\quad 0,561$

Metionina+cistina (\%) $\quad 0,897$

Lisina total (\%) 1,263

Sódio (\%) $\quad 0,222$

${ }^{1}$ Recomendações de Rostagno et al. (2000).

2 Composição por kg do produto: vit. A - 10.000 .000 UI; vit. $\mathrm{D}_{3}-2.200 .000 \mathrm{UI}$ vit. E - $6.000 \mathrm{UI}$; vit. K - $1.400 \mathrm{mg}$; vit. $\mathrm{B}_{1}-1.400 \mathrm{mg}$; vit. $\mathrm{B}_{2}-4.000 \mathrm{mg}$; vit. $\mathrm{B}_{6}-1.800 \mathrm{mg}$; vit. $\mathrm{B}_{12}$ - $10.000 \mathrm{mg}$; niacina - $25.000 \mathrm{mg}$; ácido fólico - $400 \mathrm{mg}$; ácido pantotênico - $8.500 \mathrm{mg}$; Se - $300 \mathrm{mg}$; antioxidante - $10 \mathrm{~g}$.

${ }^{3}$ Composição por kg do produto: Mn - 150.000 mg; Zn - 100.000 mg; Fe $100.000 \mathrm{mg}$; $\mathrm{Cu}-16.000 \mathrm{mg}$; I $-1.500 \mathrm{mg}$.

4 Sulfato de colistina.

${ }^{5}$ Monensina sódica.

${ }^{6}$ Análise realizada no Laboratório de Nutrição Animal do Campus II da UFPB. ${ }^{7}$ Inerte. 
As aves receberam a dieta experimental aos 19 dias de idade, quando foram submetidas a um período de adaptação de cinco dias. O período de coleta de excretas foi de 24 a 29 dias de idade, sempre às $8 \mathrm{~h}$ e às $15 \mathrm{~h}$, utilizando-se o método tradicional de coleta total de excretas, com óxido férrico a $2 \%$ como marcador no início e no final das coletas, e cálculo dos valores energéticos pela equação de Matterson et al. (1965).

O coeficiente de metabolização da energia bruta do ovo desidratado foi calculado pela relação percentual entre a energia bruta (EB) e a energia metabolizável aparente corrigida pelo balanço de nitrogênio (EMAn), de acordo com o ARC (1980). Determinou-se também a composição em matéria seca (MS), proteína bruta (PB), umidade, cinzas e matéria mineral (MM) das excretas.

O segundo experimento foi realizado no Aviário Experimental do Setor dle Avicultura do Centro de Formação de Tecnólogos (CFT), Campus III da Universidade Federal da Paraíba (UFPB), localizado no município de Bananeiras, microrregião do Brejo paraibano, no período de abril a maio de 2005.

Foram utilizados 810 pintos de corte da linhagem Cobb-500 de 1 dia de idade, nas fases pré-inicial (1 a 7 dias) e inicial (8 a 21 dias), distribuídos uniformemente por peso e sexo em boxes de $1,0 \times 1,5 \mathrm{~m}$. O delineamento experimental utilizado foi o inteiramente ao acaso, em esquema fatorial $3 \times 3$, com três níveis de ovo desidratado ( 0,2 e $4 \%$ ) e três períodos de jejum pós-eclosão (28, 40 e 52 horas), que resultaram em 9 tratamentos, cada um com 6 repetições de 15 aves. O tempo zero de jejum foi considerado o momento de alojamento dos pintinhos, 28 horas pós-eclosão.

Os níveis nutricionais das rações experimentais (Tabelas 2 e 3) foram estabelecidos de acordo com as recomendações de Rostagno et al. (2005). As aves foram sexadas para garantir que, em todos os níveis de ovo desidratado, o número de machos fosse o mesmo das fêmeas.

Foram utilizados ovos descartados para o consumo humano, colhidos diariamente no setor de Avicultura do Centro de Formação de Tecnólogos - CFT. Na quebra da casca, o conteúdo foi pesado e acondicionado em bandejas e secos em estufa com ventilação forçada a $55^{\circ} \mathrm{C}$ durante 72 horas. Em seguida, o material pré-seco foi pesado, moído e armazenado em freezer e, posteriormente, foi usado na fabricação das rações experimentais. Foram realizados testes de Salmonella no Laboratório de Controle de Qualidade de Alimentos do Centro de Formação de Tecnólogos - CFT, segundo Lanara (1981) (Laboratório Nacional de Referência Animal, Brasília-DF).

Para avaliação do desempenho produtivo, foram determinados o peso vivo (PV), os ganhos de peso diário (GPD) e total (GPT), os consumos de ração diário (CRD) e total (CRT) e a conversão alimentar (CA) nas fases de 1 a 7,1 a 14 e 1 a 21 dias de idade.

As médias de temperatura e umidade relativa do ar mínimas e máximas foram, respectivamente, de 24 e $30^{\circ} \mathrm{C}$ e

Tabela 2 - Composição das dietas experimentais utilizadas na fase de 1 a 7 dias (experimento 2$)^{1}$

\begin{tabular}{|c|c|c|c|}
\hline & \multicolumn{3}{|c|}{ Nível de ovo desidratado (\%) } \\
\hline & 0,000 & 2,000 & 4,000 \\
\hline Milho & 56,96 & 58,41 & 59,86 \\
\hline Farelo de soja & 36,72 & 34,22 & 31,70 \\
\hline Oleo de soja & 2,246 & 1,050 & 0,483 \\
\hline Fosfato bicalcico & 1,895 & 1,829 & 1,762 \\
\hline Calcário & 0,998 & 1,365 & 1,102 \\
\hline Ovo desidratado & 0,000 & 2,000 & 4,000 \\
\hline Sal comum & 0,459 & 0,435 & 0,413 \\
\hline DL-metionina & 0,240 & 0,223 & 0,206 \\
\hline L-lisina $\mathrm{HCl}(78,4 \%)$ & 0,175 & 0,173 & 0,170 \\
\hline Premix mineral $^{3}$ & 0,050 & 0,050 & 0,050 \\
\hline Premix vitamínico ${ }^{4}$ & 0,100 & 0,100 & 0,100 \\
\hline Cloreto de colina & 0,080 & 0,080 & 0,080 \\
\hline Anticoccidiano 5 & 0,013 & 0,013 & 0,013 \\
\hline Promotor de crescimento 6 & 0,015 & 0,015 & 0,015 \\
\hline Antioxidante $^{7}$ & 0,010 & 0,010 & 0,010 \\
\hline Inerte $^{8}$ & 0,027 & 0,026 & 0,028 \\
\hline \multicolumn{4}{|l|}{ Composição química } \\
\hline Proteína bruta (\%) & 21,91 & 21,91 & 21,91 \\
\hline EMAn (kcal/kg) & 2.950 & 2.950 & 2.950 \\
\hline Cálcio (\%) & 0,988 & 0,988 & 0,988 \\
\hline Fósforo disponível (\%) & 0,466 & 0,466 & 0,466 \\
\hline Metionina+cistina (\%) & 0,915 & 0,914 & 0,912 \\
\hline Metionina+cistina (\%) & 0,832 & 0,832 & 0,832 \\
\hline Metionina (\%) & 0,573 & 0,573 & 0,573 \\
\hline Metionina (\%) & 0,544 & 0,543 & 0,543 \\
\hline Lisina (\%) & 1,300 & 1,300 & 1,300 \\
\hline Lisina (\%) & 1,180 & 1,180 & 1,180 \\
\hline Arginina (\%) & 1,451 & 1,433 & 1,416 \\
\hline Arginina (\%) & 1,363 & 1,346 & 1,329 \\
\hline Treonina (\%) & 0,842 & 0,844 & 0,847 \\
\hline Treonina (\%) & 0,733 & 0,736 & 0,739 \\
\hline Triptofano (\%) & 0,273 & 0,276 & 0,280 \\
\hline Triptofano (\%) & 0,246 & 0,251 & 0,255 \\
\hline Valina (\%) & 1,010 & 1,026 & 1,042 \\
\hline Valina (\%) & 0,895 & 0,903 & 0,911 \\
\hline Sódio (\%) & 0,224 & 0,224 & 0,224 \\
\hline Cloro (\%) & 0,305 & 0,306 & 0,307 \\
\hline Potássio (\%) & 0,847 & 0,815 & 0,784 \\
\hline Balanço eletrolítico & 228,0 & 219,5 & 211,3 \\
\hline
\end{tabular}

${ }^{1}$ Recomendações de Rostagno et al. (2005).

2 Aminoácido do ovo desidratados segundo Norberg (2004).

${ }^{3}$ Composição básica do produto: sulfato de ferro, sulfato de cobre, óxido de zinco, monóxido de manganês, selenito de sódio, iodeto de cálcio, veículo Q.S.P. Níveis de garantia por $\mathrm{kg}$ do produto: Mn - $140.000 \mathrm{mg}$; Zn $120.000 \mathrm{mg}$; Fe - $100.000 \mathrm{mg}$; Cu - $18.000 \mathrm{mg}$; I - $2.000 \mathrm{mg}$, Se - $600 \mathrm{mg}$.

${ }^{4}$ Níveis de garantia por kg do produto: vit. A - 36.000.000 UI; vi. D3 - 7.400.000 UI; vit. E - 64.000 UI; vit. K3 - 8.000 mg; vit. B12 - 48.000 mg; vit. B1 - 6.400 mg; vit. B2 - $20.000 \mathrm{mg}$; vit. B6 - $9.600 \mathrm{mg}$; ácido fólico - $2.800 \mathrm{mg}$; ácido pantotênico - 44.000 mg; ácido nicotínico - 120.000 mg; biotina - 200 mg.

5 Sulfaquinoxalina 24 g; diaveridina 12 g; trimetropim 4,8 g. Excipiente q.s.p. $100 \mathrm{~g}$.

6 Bacitracina de zinco.

7 BHT = butil hidroxi tolueno.

${ }^{8}$ Inerte $=$ areia. 
Tabela 3 - Composição das dietas experimentais utilizadas na fase de 8 a 21 dias $^{1}$ (experimento 2)

\begin{tabular}{|c|c|c|c|}
\hline \multirow[t]{2}{*}{ Ingrediente (\%) } & \multicolumn{3}{|c|}{ Nível de ovo desidratado (\%) } \\
\hline & 0,000 & 2,000 & 4,000 \\
\hline Milho & 59,670 & 61,118 & 62,566 \\
\hline Farelo de soja & 33,962 & 31,451 & 28,940 \\
\hline Òleo de soja & 2,491 & 1,609 & 0,728 \\
\hline Fosfato bicalcico & 1,777 & 1,710 & 1,643 \\
\hline Calcário & 0,968 & 1,020 & 1,071 \\
\hline Ovo desidratado & 0,000 & 2,000 & 4,000 \\
\hline Sal comum & 0,441 & 0,418 & 0,396 \\
\hline DL-metionina & 0,222 & 0,205 & 0,188 \\
\hline L-lisina $\mathrm{HCl}(78,4 \%)$ & 0,174 & 0,173 & 0,171 \\
\hline Premix mineral ${ }^{3}$ & 0,050 & 0,050 & 0,050 \\
\hline Premix vitamínico 4 & 0,100 & 0,100 & 0,100 \\
\hline Cloreto de colina & 0,080 & 0,080 & 0,080 \\
\hline Anticoccidiano $^{5}$ & 0,013 & 0,013 & 0,013 \\
\hline Promotor de crescimento 6 & 0,015 & 0,015 & 0,015 \\
\hline Antioxidante $^{7}$ & 0,010 & 0,010 & 0,010 \\
\hline Inerte $^{8}$ & 0,027 & 0,028 & 0,029 \\
\hline \multicolumn{4}{|l|}{ Composição química } \\
\hline Proteína bruta (\%) & 20,877 & 20,877 & 20,877 \\
\hline EMAn (kcal/kg) & 3.000 & 3.000 & 3.000 \\
\hline Cálcio (\%) & 0,939 & 0,939 & 0,939 \\
\hline Fósforo disponível (\%) & 0,441 & 0,441 & 0,441 \\
\hline Metionina+cistina (\%) & 0,872 & 0,870 & 0,869 \\
\hline Metionina+cistina (\%) & 0,792 & 0,792 & 0,792 \\
\hline Metionina (\%) & 0,542 & 0,541 & 0,541 \\
\hline Metionina (\%) & 0,513 & 0,512 & 0,512 \\
\hline Lisina (\%) & 1,230 & 1,230 & 1,230 \\
\hline Lisina (\%) & 1,115 & 1,115 & 1,116 \\
\hline Arginina (\%) & 1,370 & 1,351 & 1,334 \\
\hline Arginina (\%) & 1,285 & 1,268 & 1,251 \\
\hline Treonina (\%) & 0,801 & 0,803 & 0,806 \\
\hline Treonina (\%) & 0,697 & 0,700 & 0,703 \\
\hline Triptofano (\%) & 0,257 & 0,260 & 0,263 \\
\hline Triptofano (\%) & 0,231 & 0,237 & 0,240 \\
\hline Sódio (\%) & 0,216 & 0,216 & 0,216 \\
\hline Cloro (\%) & 0,295 & 0,296 & 0,297 \\
\hline Potássio (\%) & 0,803 & 0,773 & 0,741 \\
\hline Balanço eletrolítico & 216,10 & 208,15 & 199,68 \\
\hline
\end{tabular}

${ }^{1}$ Recomendações de Rostagno et al. (2005).

2 Aminoácido do ovo desidratados segundo Norberg (2004).

${ }^{3}$ Composição básica do produto: sulfato de ferro, sulfato de cobre, óxido de zinco, monóxido de manganês, selenito de sódio, iodeto de cálcio, veículo Q.S.P. Níveis de garantia por kg do produto: Mn - 140.000 mg; Zn - 120.000 mg; $\mathrm{Fe}-100.000 \mathrm{mg}$; Cu - $18.000 \mathrm{mg}$; I -2.000 mg; se - $600 \mathrm{mg}$.

${ }^{4}$ Níveis de garantia por $\mathrm{kg}$ do produto: vit. A - 36.000.000 UI; vit. D3 7.400.000 UI; vit. E - $64.000 \mathrm{UI}$; vit. K3 - $8.000 \mathrm{mg}$; vit. B12 - $48.000 \mathrm{mg}$; vit. B1 - $6.400 \mathrm{mg}$; vit. B2 $20.000 \mathrm{mg}$; vit. B6 - $9.600 \mathrm{mg}$; ácido fólico - $2.800 \mathrm{mg}$; ácido pantotênico - $44.000 \mathrm{mg}$; ácido nicotínico - $120.000 \mathrm{mg}$; biotina - 200 mg.

${ }^{5}$ Sulfaquinoxalina - 24 g; diaveridina - 12 g; trimetropim - 4,8 g; excipiente q.s.p. $-100 \mathrm{~g}$.

${ }^{6}$ Bacitracina de zinco.

${ }^{7} \mathrm{BHT}=$ butil hidroxi tolueno.

${ }^{8}$ Inerte $=$ areia.

94 e 42\%, registradas no interior do galpão em aparelho termohigrômetro em dois períodos diários, às 8 e 16 h, respectivamente.

As análises estatísticas foram realizadas utilizando-se o programa SAEG - Sistema de Análises Estatísticas e Genética (Euclydes, 1982). As médias foram comparadas pelos testes F e Student Newman-Keuls, a 5\% de probabilidade.

\section{Resultados e Discussão}

O ovo desidratado apresentou 96,51\% matéria seca (MS), 3,36\% de umidade, 8,53\% de matéria mineral, 84,61\% de matéria orgânica e 51,54\% de proteína bruta(PB) (Tabela 4). O resultado de proteína bruta encontrado neste estudo confirma os obtidos por Fiqueiredo (2003), que determinou 53,56\% PB, Norberg et al. (2004), que encontraram 48,69\% PB, e Silva et al. (2004b), que determinaram 47,79\% PB.

Os valores energéticos variaram de acordo com a porcentagem de ovo desidratado na ração-referência. Com 15\% de inclusão, os valores de EMA de EMAn e o coeficiente de metabolização foram superiores aos valores determinados no nível de 30\% de substituição. Provavelmente, a menor eficiência de conversão da energia bruta em EMAn foi proporcionada pelo desbalanço energético e protéico da ração superando a capacidade dos pintos em aproveitar o excesso de nutrientes que foi perdido nas excretas. Portanto, considerou-se valor energético a média obtida nos dois níveis de ovo desidratado de 4.278,5 kcal EMAn $/ \mathrm{kg}$. O ovo desidratado apresentou valores de EMAn superiores ao do milho (4.278 vs $3.381 \mathrm{kcal}$ ) e ao do farelo de soja (2.256 kcal) e da farinha de carne e ossos (2.656 kcal), conforme os valores apresentados nas Tabelas Brasileiras de Aves e Suínos (Rostagno et al., 2005).

Em decorrência dos altos valores de EMAn e proteína bruta, o ovo desidratado apresenta-se como alimento alternativo para a nutrição de pintos na fase pré-inicial. Segundo Silva et al. (2006), a quantidade de ovos trincados e quebrados nas granjas comerciais é de aproximadamente 3\% dos ovos produzidos, o que gera perda estimada superior a 666 milhões de unidades de ovos de $60 \mathrm{~g}$ ou 40 mil toneladas de ovos em casca por ano. Esse volume expressivo pode ser aproveitado na alimentação pré-inicial de pintos como fonte de proteína de alto valor biológico e de moléculas com funções bactericida e imune. De acordo com Junqueira et al. (2001), o ovo integral é uma ótima fonte protéica, com altos níveis energéticos e de aminoácidos essenciais de grande importância na nutrição inicial de aves.

Tabela 4 - Valores energéticos do ovo desidratado, com base na matéria natural, conforme o nível de substituição na ração-referência

\begin{tabular}{lccc}
\hline \multirow{2}{*}{ Ovo desidratado $(\%)^{1}$} & \multicolumn{3}{c}{ Valor energético } \\
\cline { 2 - 4 } & EMA & EMAn & \% CMET \\
\hline 15 & $5.012,4$ & $4.609,3$ & 71,84 \\
30 & $4.228,2$ & $3.947,7$ & 61,53 \\
Média & $4.620,3$ & $4.278,5$ & 66,69 \\
\hline
\end{tabular}

${ }^{1}$ Nível de substituição da ração-referência. 
Para aproveitamento dos ovos descartados nas granjas comerciais e sua utilização na ração pré-inicial de pintos, o processo de desidratação dos ovos é uma boa forma de preservação (Bergquist, 1994), que inclui outras vantagens, como necessidade de menos espaço no estoque, facilidade de transporte, boa uniformidade e ser livre de microrganismos como Salmonella spp.

A inclusão do ovo desidratado na dieta não afetou o consumo de ração, mas o período de jejum (Tabela 5) teve efeito significativo $(P<0,05)$, uma vez que o consumo entre as aves mantidas 40 e 52 horas sem ração foi pior que o daquelas alimentadas 28 horas pós-eclosão. Esse resultado confirma o obtido por Noy \& Sklan (1999), que também constataram que o jejum prolongado afeta o consumo de ração dos pintos de corte. Portanto, sugere-se o fornecimento de ração aos pintos imediatamente após a eclosão.

Nas primeiras horas pós-eclosão, as aves utilizam a reserva nutricional do saco vitelino, que possui peso muito variável. Pintinhos alimentados imediatamente após a eclosão utilizam estas reservas mais rapidamente que aqueles que tiveram acesso tardio à ração (Vieira \& Pophal, 2000). De acordo com Bierer \& Eleazer (1965), a absorção dos nutrientes presentes no saco vitelino é mais rápida quando os pintos recebem água e ração imediatamente após a eclosão, sugerindo que o transporte das reservas do saco para o intestino delgado aumenta com a maior atividade fisiológica do intestino das aves alimentadas.

Conforme descrito por Edwards et al. (1962), aves com saco vitelino cirurgicamente removido apresentaram pior desempenho em comparação a aves de um grupo controle, também operado, mas com saco vitelino mantido, o que comprova a importância desta reserva para aves no período pós-eclosão como primeira fonte de nutrientes utilizada pelo pintinho após a emergênca, pois, quanto maior o tempo entre a eclosão e o início da ingestão de alimento e água, maior a dependência que o pintinho terá dessas reservas (Vieira \& Pophal, 2000).

A inclusão de 4\% do ovo desidratado na ração melhorou $(\mathrm{P}<0,05)$ o peso vivo (Tabela 6 ) dos pintinhos nas primeiras 12 e 24 horas de alojamento. De acordo com Longo (2002), o maior desafio da nutrição pré-inicial em aves, é a transição da dieta líquida, representada pelo conteúdo do saco vitelino rico em proteínas e gorduras, para dieta sólida, composta por carboidratos, lipídios e proteína de origem vegetal.

À eclosão, o resíduo da gema corresponde a $20 \%$ do peso corporal dos pintos e constitui fonte imediata de energia e de proteína (Fiqueiredo, 2003) para mantença e crescimento nas primeiras horas de vida (Sklan, 2003).

Os resultados indicam que a inclusão de $4 \%$ de ovo desidratado melhorou o peso corporal de pintinhos no primeiro dia de vida, entretanto piorou aos 7 dias de idade. As aves submetidas a jejum de 40 a 52 horas na fase póseclosão apresentaram menor peso, indicando que após a eclosão o fornecimento mais cedo de ração aos pintinhos é fator relevante na criação pré-inicial de pintos de corte.

Os piores resultados de peso vivo observados neste estudo foram para os pintos submetidos ao período de jejum de 52 horas, e são indicativos dos efeitos positivos da presença de ração no trato gatrointestinal sobre o cres-

Tabela 5 - Consumo de ração em pintinhos de corte alimentados com rações contendo ovo desidratado em diversos tempos pós-eclosão

\begin{tabular}{|c|c|c|c|c|c|}
\hline \multirow{3}{*}{ Ovo desidratado (OD), \% } & \multicolumn{5}{|c|}{ Consumo de ração (g) } \\
\hline & \multirow{2}{*}{$\begin{array}{c}\frac{1 / 2}{d i a} \\
\begin{array}{c}\text { Consumo total } \\
\text { de ração }\end{array}\end{array}$} & \multicolumn{2}{|c|}{1 a 5 dias } & \multicolumn{2}{|c|}{1 a 7 dias } \\
\hline & & $\begin{array}{l}\text { Consumo diário } \\
\text { de ração }\end{array}$ & $\begin{array}{l}\text { Consumo total } \\
\text { de ração }\end{array}$ & $\begin{array}{l}\text { Consumo diário } \\
\text { de ração }\end{array}$ & $\begin{array}{l}\text { Consumo total } \\
\text { de ração }\end{array}$ \\
\hline 0 & 1,36 & 12,84 & 64,20 & 15,30 & 107,09 \\
\hline 2 & 1,33 & 12,42 & 62,09 & 14,92 & 104,46 \\
\hline 4 & 1,32 & 12,38 & 61,89 & 14,76 & 103,29 \\
\hline \multicolumn{6}{|c|}{ Tempo de jejum pós-eclosão (TJPe), horas } \\
\hline 28 & $4,015 \mathrm{~A}$ & $15,29 \mathrm{~A}$ & $76,44 \mathrm{~A}$ & $17,57 \mathrm{~A}$ & $122,96 \mathrm{~A}$ \\
\hline 40 & $0,000 \mathrm{~B}$ & $12,76 \mathrm{~B}$ & $63,81 \mathrm{~B}$ & $15,09 \mathrm{~B}$ & $105,66 \mathrm{~B}$ \\
\hline 52 & $0,000 \mathrm{~B}$ & $9,59 \mathrm{C}$ & $47,93 \mathrm{C}$ & $12,32 \mathrm{C}$ & $86,22 \mathrm{C}$ \\
\hline \multicolumn{6}{|l|}{ Anova } \\
\hline Ovo desidratado & ns & \multicolumn{2}{|c|}{ ns } & \multicolumn{2}{|c|}{ ns } \\
\hline TJPe & $*$ & \multicolumn{2}{|c|}{$*$} & \multicolumn{2}{|c|}{$*$} \\
\hline OD*TJPe & ns & \multicolumn{2}{|c|}{ ns } & \multicolumn{2}{|c|}{ ns } \\
\hline CV (\%) & 26,658 & \multicolumn{2}{|c|}{6,827} & \multicolumn{2}{|c|}{4,812} \\
\hline
\end{tabular}

\footnotetext{
A,B Médias seguidas de letras maiúsculas diferentes na coluna são estatisticamente distintas $(P<0,05)$ pelo teste $F$.
} 
Tabela 6 - Peso vivo de pintinhos de corte alimentados com rações contendo ovo desidratado em diversos tempos pós-eclosão

\begin{tabular}{lrcrr}
\hline Ovo desidratado (OD), $\%$ & \multicolumn{4}{c}{ Peso vivo $(\mathrm{g})$} \\
\cline { 2 - 5 } & $1 / 2$ dia & 1 dia & 5 dias & 7 dias \\
\hline 0 & $36,24 \mathrm{~B}$ & $39,36 \mathrm{~B}$ & 98,84 & $141,52 \mathrm{~A}$ \\
2 & $36,24 \mathrm{~B}$ & $39,03 \mathrm{~B}$ & 98,00 & $137,11 \mathrm{~B}$ \\
4 & $36,81 \mathrm{~A}$ & $39,86 \mathrm{~A}$ & 99,01 & $140,16 \mathrm{AB}$ \\
\hline
\end{tabular}

Tempo de jejum pós-eclosão (TJPe), horas

\begin{tabular}{lllll}
\hline 28 & $40,33 \mathrm{~A}$ & $43,84 \mathrm{~A}$ & $114,50 \mathrm{~A}$ & $155,15 \mathrm{~A}$ \\
40 & $34,63 \mathrm{~B}$ & $40,83 \mathrm{~B}$ & $98,22 \mathrm{~B}$ & $139,50 \mathrm{~B}$ \\
52 & $34,33 \mathrm{~B}$ & $33,57 \mathrm{C}$ & $83,13 \mathrm{C}$ & $124,13 \mathrm{C}$ \\
\hline
\end{tabular}

Anova

OD

TJPe

$\mathrm{OD} * \mathrm{TJPe}$

$\mathrm{CV}(\%)$

A,B Médias seguidas de letras maiúsculas diferentes na coluna são estatisticamente distintas $(\mathrm{P}<0,05)$ pelo teste $\mathrm{F}$.

cimento inicial. De acordo com Geyra et al. (2002) pintos que têm acesso ao alimento durante as primeiras 48 horas póseclosão apresentam maior peso vivo que pintos submetidos a jejum. Maiorka et al. (2003), observaram que o pintos com acesso a ração mais cedo apresentaram pesos de fígado, duodeno e comprimento do jejuno e do íleo superiores aos dos pintos alimentados 24, 48 e 72 horas após eclosão.

Alta correlação negativa foi constatada entre o peso vivo e o atraso na oferta de ração aos pintos $(r=-0,823$; $\mathrm{P} \leq 0,0001$ ), que indica relação inversa entre o peso vivo dos pintinhos e o tempo em que as aves permaneceram em jejum, de modo que, para cada hora que o pintinho deixou de ser alimentado, houve redução de 0,08 gramas em seu peso vivo (Figura 1), que totalizou $4,6 \mathrm{~g}$ de perda de peso vivo desde o tempo 0 até as 52 horas pós-eclosão $(38,10$ vs 33,49 g), o que explica o menor peso vivo dos pintinhos que ficaram em jejum até 52 horas aos 7 dias de idade.

Houve efeito da inclusão do ovo desidratado sobre o ganho de peso de 1 a 7 dias de idade $(\mathrm{P}>0,05)$, mas a conversão alimentar não foi afetada pela inclusão de ovo desidratado na ração (Tabela 7). Estes resultados contrariam a hipótese de Silva et al. (2006) de que o ovo desidratado apresentava potencial para melhorar o desempenho das aves em ambiente convencional.

A duração do tempo de jejum após a eclosão teve efeito negativo sobre o ganho de peso $(\mathrm{P}<0,05)$, que diminuiu à medida que os pintos tiveram o fornecimento de ração retardado até 52 horas pós-eclosão (Tabela 7).

A melhoria na qualidade da ração fornecida nas primeiras idades é uma possível alternativa para alimentar pintos submetidos a atrasos na oferta de ração no período de pós-

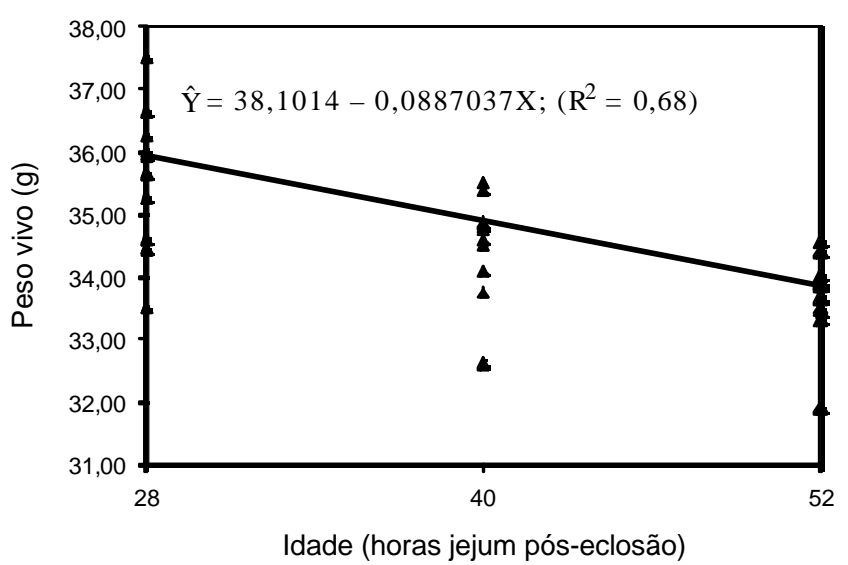

Figura 1 - Regressão do comportamento do peso vivo(PV)em diversos tempos de jejum pós-eclosão.

eclosão. Silva et al. (2004a) comparando três programas de alimentação para pintos submetidos a jejum de 72 horas de duração, concluíram que os programas com dietas préiniciais tiveram efeito positivo no desempenho, uma vez que o sistema digestivo dos pintos em situação de restrição alimentar é muito sensível à qualidade da dieta presente no lúmen intestinal. Segundo Vieira \& Pophal (2000), a adaptação à ingestão de alimentos depende do rápido desenvolvimento dos mecanismos de digestão e absorção, que dependem diretamente do estímulo dado pela passagem do alimento pelo trato digestório.

As alterações anatômicas do aparelho digestivo dos frangos de corte nos primeiros dias de vida são significativas. Após a eclosão, os pesos do pró-ventrículo, da moela e do intestino delgado aumentam mais rapidamente que o peso corporal das aves e os pesos dos outros tecidos (Junqueira et al., 2001). Geyra et al. (2001), examinando as alteraçõs do intestino e a dinâmica enterocítica em pintos em 12 dias pós-eclosão, observaram que as alterações mais significativas ocorrem nas primeiras 24 horas póseclosão.

Não houve efeito significativo $(\mathrm{P}<0,05)$ do ovo desidratado sobre o desempenho de 1 a 14 e de 1 a 21 dias de idade (Tabela 8). Junqueira et al. (2001) observaram efeito negativo da inclusão de $5 \%$ de ovo desidratado na ração sobre o desempenho das aves até 21 dias de idade. Os resultados obtidos por Junqueira et al. (2001) podem ser explicados pelos altos níveis de inclusão do ovo desidratado na ração $(5 ; 10 ; 15 ; 20$ e $25 \%)$ ou pelo balanceamento das rações, feito por estes autores com base nos percentuais de aminoácido total, uma vez que a digestibilidade de alguns aminoácidos, metionina, cistina e valina, são maiores no ovo desidratado que no farelo de soja (Norberg et al., 2004), 
Tabela 7 - Variação de peso diário, ganho de peso total e conversão alimentar de pintos de corte alimentados com rações contendo ovo desidratado em diversos tempos de jejum pós-eclosão

\begin{tabular}{|c|c|c|c|c|c|c|}
\hline & \multicolumn{2}{|c|}{ Variação de peso diário (g) } & \multicolumn{2}{|c|}{ Ganho de peso total (g) } & \multicolumn{2}{|c|}{ Conversão alimentar $(\mathrm{kg} / \mathrm{kg}$} \\
\hline Ovo desidratado (OD), \% & $1 / 2$ dia & 1 dia & 1 a 5 dias & 1 a 7 dias & 1 a 5 dias & 1 a 7 dias \\
\hline 0 & 0,730 & 3,84 & 63,33 & $106,00 \mathrm{~A}$ & 1,015 & 1,012 \\
\hline 2 & 0,744 & 3,53 & 62,50 & 101,61B & 1,000 & 1,027 \\
\hline 4 & 0,885 & 3,93 & 63,08 & $104,23 \mathrm{AB}$ & 0,990 & 0,986 \\
\hline \multicolumn{7}{|c|}{ Tempo de jejum pós-eclosão (TJPe), horas } \\
\hline 28 & $4,63 \mathrm{~A}$ & $8,14 \mathrm{~A}$ & $78,79 \mathrm{~A}$ & $119,45 \mathrm{~A}$ & 0,972 & $1,031 \mathrm{~A}$ \\
\hline 40 & $-1,07 \mathrm{~B}$ & $5,01 \mathrm{~B}$ & $62,40 \mathrm{~B}$ & $103,67 \mathrm{~B}$ & 1,025 & $1,020 \mathrm{~A}$ \\
\hline 52 & $-1,19 \mathrm{~B}$ & $-1,84 \mathrm{C}$ & $47,72 \mathrm{C}$ & $88,73 \mathrm{C}$ & 1,010 & $0,974 \mathrm{~B}$ \\
\hline \multicolumn{7}{|l|}{ Anova } \\
\hline OD & ns & ns & ns & $\mathrm{L}^{*}$ & ns & ns \\
\hline TJPe & $\mathrm{L} * *$ & $\mathrm{~L} * *$ & $\mathrm{~L} * *$ & $\mathrm{~L} * *$ & ns & $\mathrm{L}^{*}$ \\
\hline OD*TJPe & ns & ns & ns & ns & ns & ns \\
\hline CV (\%) & 74,34 & 18,80 & 7,41 & 5,03 & 6,45 & 5,55 \\
\hline
\end{tabular}

A,B Médias seguidas de letras maiúsculas diferentes na coluna são estatisticamente distintas $(\mathrm{P}<0,05)$ pelo teste $\mathrm{F}$.

$\mathrm{L}^{*}=$ efeito linear $(\mathrm{P}<0,05) ; \mathrm{L}^{* *}=$ efeito linear $(\mathrm{P}<0,01)$.

Tabela 8 - Consumo de ração, peso vivo, ganho de peso e conversão alimentar de pintos de corte alimentados com rações contendo ovo desidratado em diversos tempos de jejum pós-eclosão

\begin{tabular}{|c|c|c|c|c|c|c|}
\hline \multirow[b]{2}{*}{ Ovo desidratado (OD), \% } & \multicolumn{6}{|c|}{1 a 14 dias } \\
\hline & $\begin{array}{l}\text { Consumo diário } \\
\text { de ração (g) }\end{array}$ & $\begin{array}{l}\text { Consumo total } \\
\text { de ração (g) }\end{array}$ & Peso vivo (g) & $\begin{array}{l}\text { Ganho de } \\
\text { peso diário (g) }\end{array}$ & $\begin{array}{c}\text { Ganho de } \\
\text { peso total (g) }\end{array}$ & $\begin{array}{c}\text { Conversão } \\
\text { alimentar }(\mathrm{kg} / \mathrm{kg})\end{array}$ \\
\hline 0 & 46,40 & 649,55 & 407,22 & 26,55 & 371,71 & 1,764 \\
\hline 2 & 45,22 & 633,11 & 400,82 & 26,09 & 365,32 & 1,744 \\
\hline 4 & 46,76 & 654,62 & 398,83 & 25,92 & 362,60 & 1,808 \\
\hline \multicolumn{7}{|c|}{ Tempo de jejum pós-eclosão (TJPe), horas } \\
\hline 28 & $47,36 \mathrm{~A}$ & $663,04 \mathrm{~A}$ & $429,56 \mathrm{~A}$ & $28,13 \mathrm{~A}$ & $393,85 \mathrm{~A}$ & $1,688 \mathrm{~B}$ \\
\hline 40 & $45,92 \mathrm{AB}$ & $642,93 \mathrm{AB}$ & $408,06 \mathrm{~B}$ & $26,59 B$ & $372,23 \mathrm{~B}$ & $1,731 \mathrm{~B}$ \\
\hline 52 & $45,09 \mathrm{~B}$ & $631,31 \mathrm{~B}$ & $369,26 \mathrm{C}$ & $23,84 \mathrm{C}$ & $333,85 \mathrm{C}$ & $1,898 \mathrm{~A}$ \\
\hline \multirow[t]{2}{*}{ CV (\%) } & \multicolumn{2}{|c|}{5,054} & 5,408 & \multicolumn{2}{|c|}{5,906} & 6,490 \\
\hline & \multicolumn{6}{|c|}{1 a 21 dias } \\
\hline 0 & 53,94 & 1132,78 & 799,16 & 36,36 & 763,65 & 1,494 \\
\hline 2 & 53,61 & 1125,76 & 793,02 & 36,07 & 757,52 & 1,491 \\
\hline 4 & 54,14 & 1136,91 & 796,32 & 36,21 & 760,39 & 1,499 \\
\hline \multicolumn{7}{|c|}{ Tempo de jejum pós-eclosão (TJPe), horas } \\
\hline 28 & $57,68 \mathrm{~A}$ & $1211,35 \mathrm{~A}$ & $828,83 \mathrm{~A}$ & $37,77 \mathrm{~A}$ & $793,13 \mathrm{~A}$ & $1,532 \mathrm{~A}$ \\
\hline 40 & $50,37 \mathrm{~A}$ & $1057,68 \mathrm{~A}$ & $811,79 \mathrm{~A}$ & $36,95 \mathrm{~A}$ & $775,97 \mathrm{~A}$ & $1,368 \mathrm{~B}$ \\
\hline 52 & $53,64 \mathrm{~B}$ & $1126,42 B$ & $747,88 \mathrm{~B}$ & $33,93 \mathrm{~B}$ & $712,47 \mathrm{~B}$ & $1,584 \mathrm{~A}$ \\
\hline \multicolumn{7}{|l|}{ Anova } \\
\hline OD & ns & ns & ns & ns & ns & ns \\
\hline $\mathrm{TJPe}$ & $\mathrm{L} * *$ & $\mathrm{~L} * *$ & $\mathrm{~L} * *$ & $\mathrm{~L} * *$ & $\mathrm{~L} * *$ & $* *$ \\
\hline OD*TJPe & ns & ns & ns & ns & ns & ns \\
\hline CV (\%) & \multicolumn{2}{|c|}{5,890} & 6,469 & \multicolumn{2}{|c|}{7,017} & 7,283 \\
\hline
\end{tabular}

A,B Médias seguidas de letras maiúsculas diferentes na coluna são estatisticamente distintas $(\mathrm{P}<0,05)$ pelo teste $\mathrm{F}$.

$\mathrm{L}^{*}=$ efeito linear $(\mathrm{P}<0,05) ; \mathrm{L}^{* *}=$ efeito linear $(\mathrm{P}<0,01)$. 
o que pode ter provocado efeito de desbalanço aminoacídico nos pintos alimentados por Junqueira et al. (2001), causando redução no consumo, ganho de peso e piorando a conversão alimentar.

As aves submetidas a atrasos no fornecimento de ração apresentaram consumo, peso vivo e ganho de peso inferiores em comparação às alimentadas mais cedo (Tabela 8). Esse resultado indica que o ganho compensatório do pintinho submetido a jejum prolongado no período pós-eclosão não é suficiente para corrigir o atraso no crescimento causado pela oferta tardia da primeira alimentação pós-eclosão, o que reflete em piores ganhos de peso até 21 dias de idade. Segundo Nir \& Levanon (1993), a perda de peso imposta aos pintinhos que receberam ração após 40 a 52 horas de eclosão (12 e 24 horas pós-alojamento) atrasa de 1 a 2 dias, respectivamente, o tempo para que as aves atinjam o peso de abate das aves alimentadas logo após a eclosão. Atrasos de 24 horas no alojamento determinam perdas de peso inicial aos 49 dias de $110 \mathrm{~g}$ (Vieira \& Moran, 1999a).

A inclusão de até $4 \%$ de ovo desidratado na ração de 1 a 21 dias não afeta o desempenho de frangos de corte até 42 dias de idade, apesar da expectativa de que a inclusão de um produto rico em energia e aminoácidos na ração préinicial estimulasse o desempenho das aves. Junqueira et al. (2001) observaram que o desempenho de pintos de corte reduziu com a adição de 5\% de ovo desidratado na ração e, mais recentemente, Silva et al. (2007) concluíram que a inclusão do ovo desidratado na ração de pintos não deve ser superior a 1\% em rações fareladas, pois níveis superiores, ainda por razões desconhecidas, podem diminuir o desempenho das aves na fase pós-eclosão.

Alguns autores relatam que, ao retardar o início da alimentação das aves, ocorre atraso na maturação do sistema digestivo, que é estimulado pela presença dos nutrientes da ração no trato gastrointestinal (Wyatt et al., 1985). Noy et al. (2002), utilizando diferentes níveis de macronutrientes para pintos durante a primeira semana, observaram efeito significativo sobre o consumo, o peso vivo e a eficiência alimentar em comparação a aves mais velhas, sugerindo que a limitação de aminoácidos e energia da dieta fornecida logo após a eclosão afeta o crescimento das aves.

Neste trabalho, a importância de alimentar os pintos de corte logo após a eclosão confirma resultados obtidos por vários autores de que rápido desenvolvimento das atividades de digestão e absorção da mucosa intestinal é substrato dependente, ou seja, a presença do alimento sólido no trato digestivo promove o desenvolvimento da atividade de digestão dos nutrientes (Noy \& Sklan, 1999). Segundo Noy et al. (2002), quanto mais cedo o estímulo da alimentação, menor a perda de peso inicial pós-eclosão, maior a taxa de crescimento e melhor a uniformidade de peso das aves até 21 dias de idade. O desenvolvimento do trato gastrintestinal durante a primeira semana de vida é essencial para que o frango de corte possa expressar seu potencial genético máximo para ganho de peso, diminuindo o tempo necessário para que as aves atinjam o peso de abate (Nitsan, 1995).

O ganho de peso de pintos de corte durante a fase inicial está diretamente relacionado à eficiência do manejo alimentar. O uso de dietas pré-iniciais é o reconhecimento da importância da nutrição no crescimento das linhagens modernas nos primeiros dias pós-eclosão e suas influências no peso final do frango de corte. De acordo com Vieira \& Pophal (2000), na formulação de uma dieta pré-inicial, deve-se considerar as características únicas dos animais nesta fase de vida e, segundo Penz Jr. \& Vieira (1998), a dieta pré-inicial deve ser produzida com os melhores e mais caros ingredientes disponíves na fábrica de ração, pois a quantidade consumida nesta fase corresponde somente a cerca de 3,5\% do total da dieta que será consumida pelos frangos de corte até o abate.

Futuros estudos devem ser realizados para avaliar se existe efeito do ovo desidratado de galinhas imunizadas contra Eimeria tenella, E. acervulina e E. maxima no desempenho de pintos alimentados com ou sem antibióticos e anticoccidianos na ração.

\section{Conclusões}

O ovo desidratado apresenta 51,54\% de proteína e $4.278 \mathrm{kcal} / \mathrm{kg}$ de energia metabolizável aparente corrigida pelo balanço de nitrogênio e pode ser usado em níveis de até $4 \%$ em rações para pintos de corte nas fases pré-inicial e inicial. O jejum pós-eclosão reduz o desempenho, portanto, recomenda-se evitar atrasos na oferta de ração aos pintos de corte nas primeiras horas de vida.

\section{Literatura Citada}

AGRICULTURAL RESEARCH COUNCIL - ARC. The nutrient requirements of farm animals. London: 1980. 351p.

BERGQUIST, D.H. Egg dehydrated. In: STANDELMAN, W.J.; COTTERILL, O.J. (Eds.) Egg science and technology. New York: Food Products Press, 1994. p.335-376.

BIERER, B.W.; ELEAZER T.H. Effect of feed and water deprivation on yolk utilization in chicks. Poultry Science, v.44, p.16081609, 1965.

EDWARDS, H.M.; MARION, J.E.; DRIGGERS, J.C. et al. Response of deutectomized chicks to dietary fat supplementation. Poultry Science, v.41, p.1050-1052, 1962.

EUCLYDES, R.F. Sistema de Análises Estatísticas e Genéticas - SAEG. Manual do Usuário. Versão 5.0. Viçosa, MG: Universidade Federal de Viçosa, 1982. 49p.

FIQUEIREDO, A.N.; MIYADA, V.S.; UTIYAMA, C.E. et al. O ovo em pó na alimentação de leitões recém-desmamados. Revista Brasileira de Zootecnia, v.32, n.6, p.1901-1911, 2003 (supl. 2). 
GEYRA, A.; UNI, Z.; SKLAN, D. et al. Enterocyte dynamics and mucosal development in the posthatch chicks. Poultry Science, v.80, p.776-782, 2001.

GEYRA, A.; UNI, Z.; GAL-GALBER, O. et al. Starving affects CDX gene expression during small intestinal development in the chick. Journal of Nutrition, v.132, p.911-917, 2002.

JUNQUEIRA, O.M.; ARAÚJO, L.F.; ARAÚJO, C.S.S. et al. Desempenho de frango de corte alimentado com ovo em pó. Revista Brasileira de Ciência Avícola, v.3, n.1, p.65-73, 2001.

LILBURN, M.S. Practical aspects of early nutrition for poultry. Journal of Applied Poultry Research, v.7, p.420-442, 1998.

LONGO, F.A.; MENTEM, J.F.M.; PEDROSO, A.A. et al. Energia metabolizável de carboidratos para frangos de corte na fase pré-inicial. Revista Brasileira de Ciência Avícola, v.4, suplemento 4, p.44, 2002.

MAIORKA, A.; SANTIM, E.; DAHLKE, F. et al. Posthatching water and feed deprivation affect the gastrointestinal tract and intestinal mucosal development of broiler chicks. Journal of Applied Poultry Research, v.12, p.483-492, 2003.

MATTERSON, L.D.; POTTER, L.M.; SINGSEN, E.P. et al. The metabolizable energy of feed ingredients for chickens. Research Report, v.7, p.3-11, 1965.

MINISTÉRIO DA AGRICULTURA. SECRETARIA NACIONAL DE DEFESA AGROPECUÁRIA. LABORATÓRIO NACIONAL DE REFERENCIA ANIMAL - LANARA. Métodos analíticos Oficiais para controle de produtos de origem animal e seus ingredientes. II - Métodos físicos e químicos. Brasília, Cap.XXI p.1-2, 1981.

NIR, I.; LEVANON, M. Effect of posthatch holding time on performace and on residual yolk and level composition. Poultry Science, v.72, p.1994-1997, 1993.

NITSAN, Z. The development of digestive enzime tract in posthached chicks. In: EUROPEAN SYMPOSIUM ON POULTRY NUTRITION, 1995, Altalya. Proceedings... Antalya: WPSA, 1995. p.21-28.

NORBERG, S.E.; DILGER, R.N.; DONG, H. et al. of energy and amino acids of spray-dried egg, plasma protein and soybean meal by ducks. Poultry Science, v.83, p.939-945, 2004.

NOY, I.; SKLAN, D. Nutrient use in chicks during the first week posthatch. Poultry Science, v.81, p.391-399, 2002.

NOY, I.; SKLAN, D. Energy utilization in newly hatched chicks. Poultry Science, v.78, p.1750-1756, 1999.
PENZ JR., A.M.; VIEIRA, S.L. Nutrição na primeira semana. In: CONFERÊNCIA APINCO DE CIÊNCIA E TECNOLOGIA AVÍCOLAS, 1998, Campinas. Anais... Campinas: Fundação Apinco de Ciência e Tecnologia Avícolas, 1998. p.121-39.

ROSTAGNO, H.S.; ALBINO, L.F.T.; DONZELE, J.L. et al. Tabelas brasileiras para suínos e aves: composição de alimentos e exigências nutricionais. Viçosa, MG: Universidade Federal de Viçosa, 2000. 141p.

ROSTAGNO, H.S.; ALBINO, L.F.T.; DONZELE, J.L. et al. Tabelas brasileiras para suínos e aves: composição de alimentos e exigências nutricionais. Viçosa, MG: Universidade Federal de Viçosa, 2005. 186p.

SILVA, J.H.V., RIBEIRO, M.L.G.; ROCHA, M.R.F. et al. Programas com dietas pré-iniciais melhoram o desempenho de pintos de corte após jejum de 72 horas de duração. Revista Brasileira de Ciência Avícola, suplemento, v.6, p.95, 2004a.

SILVA, J.H.V.; RIBEIRO, M.L.G.; ROCHA, M.R.F. et al. Retirada de antimicrobianos e inclusão de ovo desidratado na dieta préinicial de pintinhas leves e semi-pesadas alojadas em ambiente limpo e sujo. Revista Brasileira de Ciência Avícola, suplemento, v.6, p.208, 2004b.

SILVA, J.H.V.; JORDÃO FILHO, J.; SILVA, E.L. et al. Efeito da substituição dos antimicrobianos pelo ovo desidratado na fase pré-inicial de frangas de dois grupos genéticos alojadas em camas nova e reciclada. Revista Brasileira de Zootecnia, v.35, p.2077-2084, 2006.

SILVA, J.H.V.; TEIXEIRA, E.N.M.; RIBEIRO, M.L.G. et al. Aproveitamento de ovos com avarias de casca na alimentação de pintos de corte. Revista AveWorld, v.30, p.28-36, 2007.

SKLAN, D. Fat and carbohydrate use in posthatch chicks. Poultry Science, v.82, p.117-122, 2003.

VIEIRA, S.L.; MORAN JR., E.T. Effects of egg of origin and chick post-hatch nutrition on broiler live performance and meat yields. World's Poultry Science Journal, v.55, p.125-142, 1999a.

VIERA, S.L.; POPHAL, S. Nutrição pós-eclosão de frangos de corte. Revista Brasileira de Ciência e Tecnologia Avícola, v.7, p.189-199, 2000.

WYATT, C.L.; WEAVER JR., W.D.; BEANE, W.L. Influence of egg size, eggshell quality and posthach holding time on broiler performance. Poultry Science, v.64, p.2049-55, 1985. 